\title{
Learners' evaluation of a navigation support tool in distance education
}

Citation for published version (APA):

Bolman, C., Waterink, W., Janssen, J., Tattersall, C., Van den Berg, B., Van Es, R., \& Koper, R. (2007). Learners' evaluation of a navigation support tool in distance education. Journal of Computer Assisted Learning, 23(5), 384-392. https://doi.org/10.1111/j.1365-2729.2007.00223.x

DOI:

10.1111/j.1365-2729.2007.00223.x

Document status and date:

Published: 13/02/2007

Document Version:

Peer reviewed version

Document license:

CC BY-NC-ND

Please check the document version of this publication:

- A submitted manuscript is the version of the article upon submission and before peer-review. There can be important differences between the submitted version and the official published version of record. People interested in the research are advised to contact the author for the final version of the publication, or visit the DOI to the publisher's website.

- The final author version and the galley proof are versions of the publication after peer review.

- The final published version features the final layout of the paper including the volume, issue and page numbers.

Link to publication

\section{General rights}

Copyright and moral rights for the publications made accessible in the public portal are retained by the authors and/or other copyright owners and it is a condition of accessing publications that users recognise and abide by the legal requirements associated with these rights.

- Users may download and print one copy of any publication from the public portal for the purpose of private study or research.

- You may not further distribute the material or use it for any profit-making activity or commercial gain

- You may freely distribute the URL identifying the publication in the public portal.

If the publication is distributed under the terms of Article 25fa of the Dutch Copyright Act, indicated by the "Taverne" license above, please follow below link for the End User Agreement:

https://www.ou.nl/taverne-agreement

Take down policy

If you believe that this document breaches copyright please contact us at:

pure-support@ou.nl

providing details and we will investigate your claim.

Downloaded from https://research.ou.nl/ on date: 26 Apr. 2023 


\title{
Learners' evaluation of a navigation support tool in distance education
}

\author{
C. Bolman, C. Tattersall, W. Waterink, J. Janssen, B. van den Berg, R. van Es \& R. Koper
}

Open University of the Netherlands, Heerlen, the Netherlands

\begin{abstract}
This article investigates the usability of a navigation support tool, which guides learners by generating advice on the next best step to take in a self-study e-learning course. The article draws on log data and responses from online questionnaires to provide insights into learners' evaluation of the tool, their adherence to the advice and their expectations of self-efficacy. The theoretical underpinnings of the work are described together with the experimental set-up. Results show that more than half of the learners in the experimental group adhered to the advice and held the opinion that the advice stimulated them to proceed with the course. Learners expressed a need to know what the advice was based on which can be seen as an essential element in future development of the tool.
\end{abstract}

Keywords adherence, navigation support tool, self-efficacy, self-organized indirect social navigation, usefulness.

\section{Introduction}

Research shows that educational yield and learner attrition are in need of improvement in higher online distance education (Cookson 1990; Moonen 1997; Yorke 1999; Lorenzetti 2002; Xenos et al. 2002; Rovai 2003; Simpson 2004). One of the factors contributing to the problem is the limited degree of guidance available to learners when navigating through the curriculum (Yorke 1999). When self-directed learners assume responsibility for choosing and sequencing learning modules, navigational difficulties can lead to learners 'not reaching their goals, or taking unduly long to do so' (Tattersall et al. 2005, p. 110). A study reported by Simpson (2004) found that one-fifth of those withdrawing from a study cited 'inadequate course choice guidance' as a reason for dissatisfaction.

Accepted: 12 December 2006

Correspondence: Catherine Bolman (PhD), Faculty of Psychology, Open University of the Netherlands, Valkenburgerweg 177, $6401 \mathrm{DL}$ Heerlen, The Netherlands. Email: catherine.bolman@ou.nl
One of the responses to these issues has been the development of navigation support tools. Janssen et al. (in press) describe the experimental evaluation of such a tool in a modular online course. Learners' interaction in the course is channeled through the tool, which gives an overview of the course modules showing a list of already completed modules and a list of the modules still to be completed. In addition, the tool provides advice on the next best module to study, based on the number of times a module had been successfully completed by other learners (Koper 2005). The advice can be configured to be shown or hidden, and is visible in Fig 1.

Results showed that learners who were exposed to the navigation tool and received advice about the next best step to follow in the course completed the course more often, and made significantly more progress through the course, than students who were not exposed to the navigation tool.

Janssen et al.'s experimental study focused solely on the tool's contribution to improved educational yield. This article describes a follow-on study, conducted after the experimental period, which broadens the tool's evaluation to include learners' views on its usefulness, 


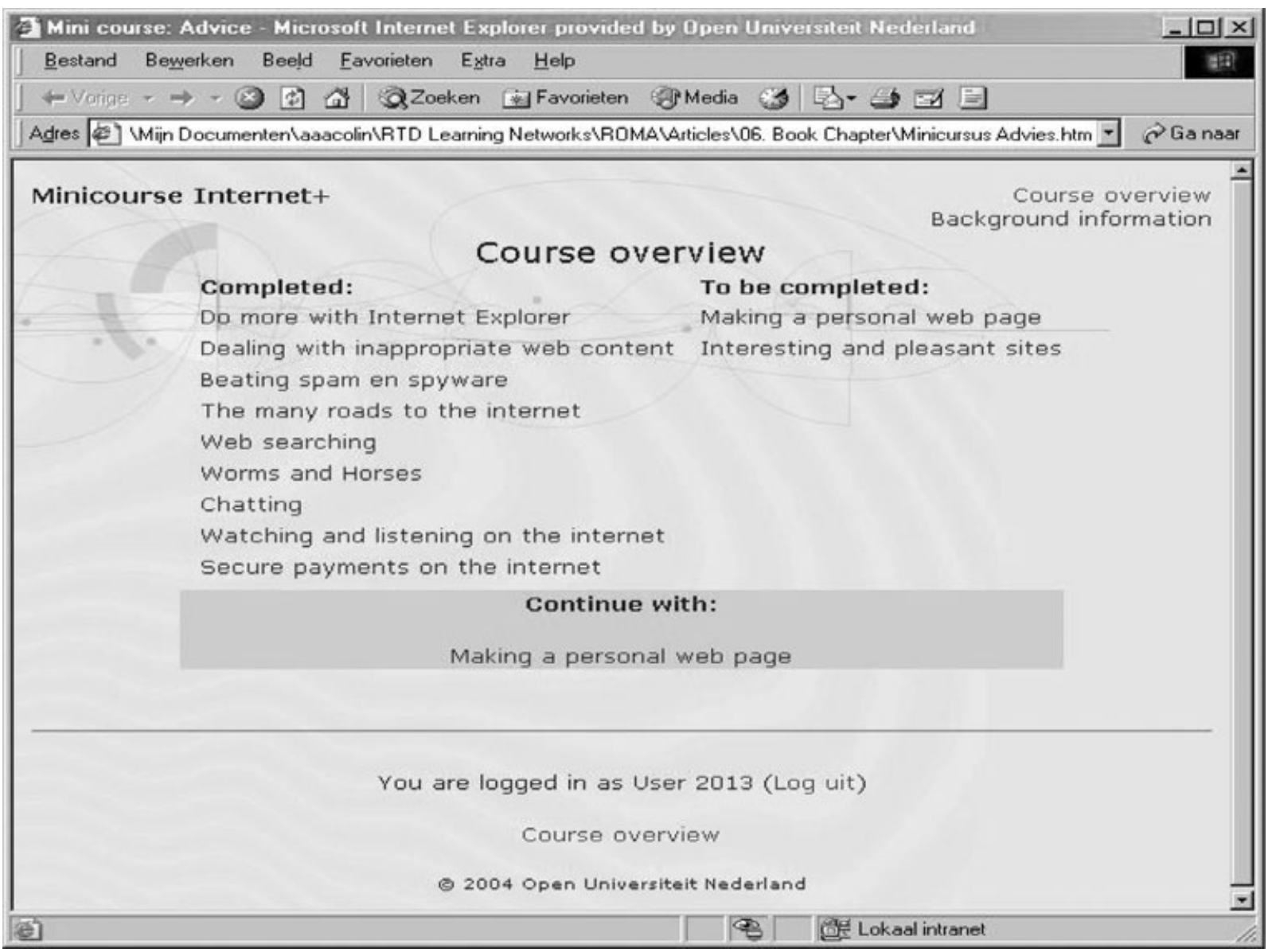

Fig 1 The navigation support tool which gives an overview of the course modules showing a list of already completed modules (left-hand side), a list of the modules still to be completed (right-hand side) and advice on the next best module to study.

and on the degree of their adherence to the generated advice. Furthermore, the study examines if Social Cognitive Theory (Bandura 1986), and in particular the notion of self-efficacy, could inform further refinement of the tool to increase its effects. Self-efficacy is defined as 'an individual's belief in one's capability to organize and execute the courses of action required to produce given attainments' (Bandura 1997, p. 3). In several studies, computerized guidance programs (e.g. Fukuyama et al. 1988; Waiman et al. 2003) have been shown to increase self-efficacy expectations towards task completion and task completion itself. Higher self-efficacy levels have been found to lead to increased levels of performance across a variety of tasks (e.g. Frayne \& Geringer 1994; Bandura 1997; Stajkovic \& Luthans 1998). Several studies (Vrught et al. 1997, 2002; Pietsch et al. 2003) and a meta-analysis (Multon \& Brown 1991) reveal that academic students (though not specifically in online distance education) with high self-efficacy levels had better study results and showed more persistence in certain academic majors. Specifically in distance education, Tennant and Pogson (1995) found high self-efficacy levels to be predictive for successful study achievement. Furthermore, self-efficacy has been found to influence the perceived ease of use and user satisfaction with computerized guidance programs (Venkathesh \& Davis 1996; Jarupathirun \& Zahedi in press). This work suggests that incorporating selfefficacy enhancing strategies in the navigational support could be used to increase its effects on educational yield.

Given this background, this article reports on and investigates the following research questions:

- Did students adhere to the advice generated from the tool; if not, on which grounds did they decide on the next module to study? 
- Did students appreciate and trust the advice?

- Did the advice stimulate students to proceed with the next module?

- Did the advice help the students in planning the course?

- Were self-efficacy expectations about course completion associated with satisfaction and adherence to the advice?

- Were self-efficacy expectations associated with course completion?

- Did the tool influence self-efficacy expectations about course completion?

\section{Method}

\section{Study design and procedure}

The experimental study revolved around a free course addressing introductory Internet skills. Learners were recruited from staff and students of The Open University of the Netherlands, together with friends and family. The recruitment announcement highlighted that the course was designed to test new technology, that it would take approximately $22 \mathrm{~h}$ to study, that the course would be available for 3 months starting in March 2005 and that its completion would be rewarded with a certificate.

Participants studying the course were randomly assigned to a control or experimental group. In the instructions given at the start of the study, learners were told they were free to study the modules in any order. The order of the list of modules still to be completed was reshuffled each time the page was viewed so that there would be no effect in learners' sequencing of modules because of their presentation in a fixed list. Participants were informed of this aspect of the tool, but were not told why this was the case. Learners in the experimental group were provided with advice on the next best step to proceed with and were advised to follow this recommendation. The control group was not exposed to this advice, but all other aspects of the course were identical in both groups.

At the start of the course, learners were asked to fill in a questionnaire on age, gender, educational level and computer skills. When the course closed (3 months after the start), all learners who had logged into their assigned site (which differed per condition) received an e-mail with a request to complete the online course evaluation questionnaire for learners, which is the subject of this article.

\section{Data}

Two types of data were gathered. First, logs of module completion were used - modules were completed through a multiple-choice quiz, with a threshold score of $60 \%$. Each learner's completion of each module is logged by the system, together with the date of completion. The second source of information is learners' answers to various online questionnaires. These were used to gather socio-demographic information for both experimental and control groups (age, gender, educational level, level of computer skills), general courserelated evaluation [time spent on the course, reason for not completing the whole course (if applicable) and learners' perceived increase in knowledge and skills as a result of the course] and information on learners adherence to the advice and self-efficacy expectations.

Inevitably, parts of the questionnaire differed between the experimental and control group. Table 1 presents the categories, questions and answer categories used in the questionnaires.

Self-efficacy expectations were measured identically in both groups using a scale developed specifically for this study, drawing on appropriate guidelines (Ajzen 1991). The self-efficacy scale score was calculated by taking together and averaging the scores on the three self-efficacy questions (Cronbach's standardized $\alpha=$ 0.67). Perceived stimulation of the advice was also measured identically in both groups. It was measured by two questions which were transformed into the stimulationscale by taking them together and averaging them ( $r=$ 0.59 for the experimental group, $r=0.50$ for the control group).

\section{Analyses}

To study how learners evaluated the navigation tool, descriptive analyses were performed. Chi-squared tests were conducted to test for differences between the experimental and control group in the questions that were equal in both groups (see Table 1). Pearson correlations were computed between adherence and the selfefficacy scale and between stimulation-scale and the self-efficacy scale. $t$-tests were conducted to test whether the navigation tool resulted in higher selfefficacy levels and higher perceived knowledge and skills in the experimental compared with the control group. Differences were considered significant when 


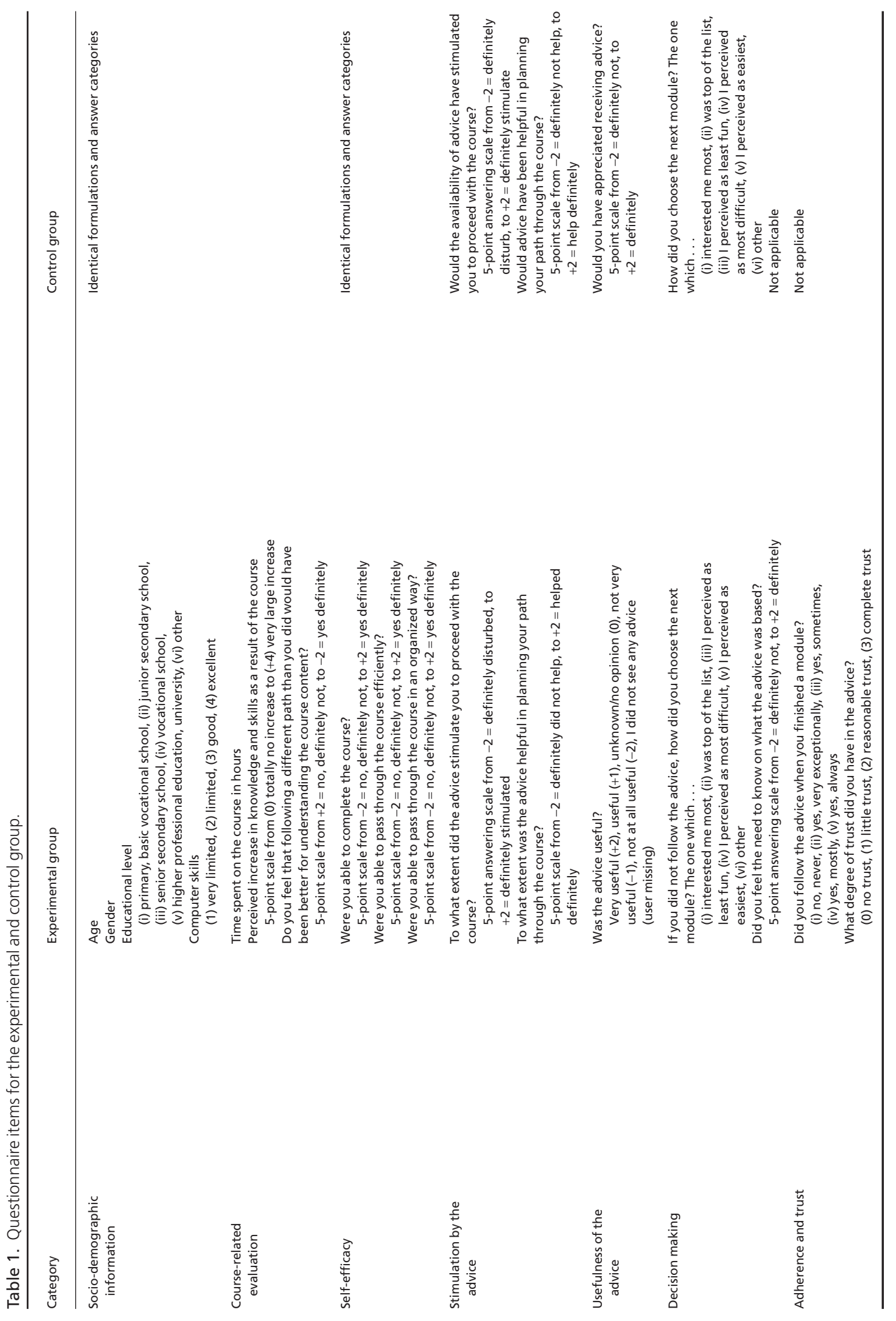


Table 2. Responses of learners in experimental group to questions regarding adherence to and trust in the advice.

\begin{tabular}{llc}
\hline Question & Answer categories & Experimental group (\%) \\
\hline Did you follow the advice & Always & 13.1 \\
when you finished a module? & Mostly & 41.1 \\
& Sometimes & 32.6 \\
& Very exceptionally & 6.3 \\
What degree of trust did you have & Never & 6.9 \\
in the advice? & Complete trust & 25 \\
& Reasonable trust & 56.5 \\
& Little trust & 17.3 \\
Did you feel the need to know on & No trust & 1.2 \\
what the advice was based? & Definitely & 13.9 \\
& Yes & 43.4 \\
\hline
\end{tabular}

$P<0.05$. All analyses were performed using sPSS 10.0.5.

\section{Results}

A group of 1011 people initially showed interest in taking the course. They were randomly assigned to either the experimental group or control group and were given login details accordingly. Twenty per cent ( $n=203$ ) did not log into their assigned course site, and this group is excluded from this article's analyses. This leaves 808 learners who entered the course sites; 398 in the control group and 410 in the experimental group. Response rates on the questionnaire on sociodemographics were about $60 \%$, showing that overall there were more women $(59 \%)$, people over 45 years old $(57 \%)$ and people with an advanced educational level (higher professional education or university level; $63 \%$ ). Finally, $48 \%$ said their computer skills were poor or very poor.

Table 2 presents responses from learners in the experimental group with respect to adherence to, and trust in, the advice. Note that the number of respondents differs per question as not all learners answered all questions. On average, half of the respondents answered the online learners' evaluation questionnaire. Slightly more than half of them followed the advice most of the time or always and almost $82 \%$ expressed trust in the advice. More than half of the experimental learners expressed the need to know the underlying basis for the advice.
Table 3 presents the responses to the questions on the experience of learners in the experimental group with the tool. Learners in the control group answered these questions hypothetically. Therefore, responses are only reported descriptively and were not tested on significant differences. Notable is that fewer learners in the experimental group reported the tool to be stimulating and helpful, compared with the control group. In both groups, comparable percentages of learners found the advice (very) useful. Learners in both groups most often chose as next module the one that interested them most. The percentage was, however, higher in the experimental group. A higher percentage of control group members than experimental group members chose the module that was top of the list.

Table 4 shows the results of an analysis of differences between the groups, revealing that the experimental learners had significantly higher scores than control learners in their perceived increase in knowledge and skills in the Internet domain as a result of the course. There were no differences in hours spent on the course nor in the judgement on the path followed through the course (sequence of modules).

Table 5 presents the correlations between the scales on self-efficacy, usefulness, adherence, stimulation and course completion for learners in the experimental group. As expected, self-efficacy expectations were positively correlated with the number of modules completed (course completion). To a lesser extent, they were also correlated with stimulation and adherence to the 


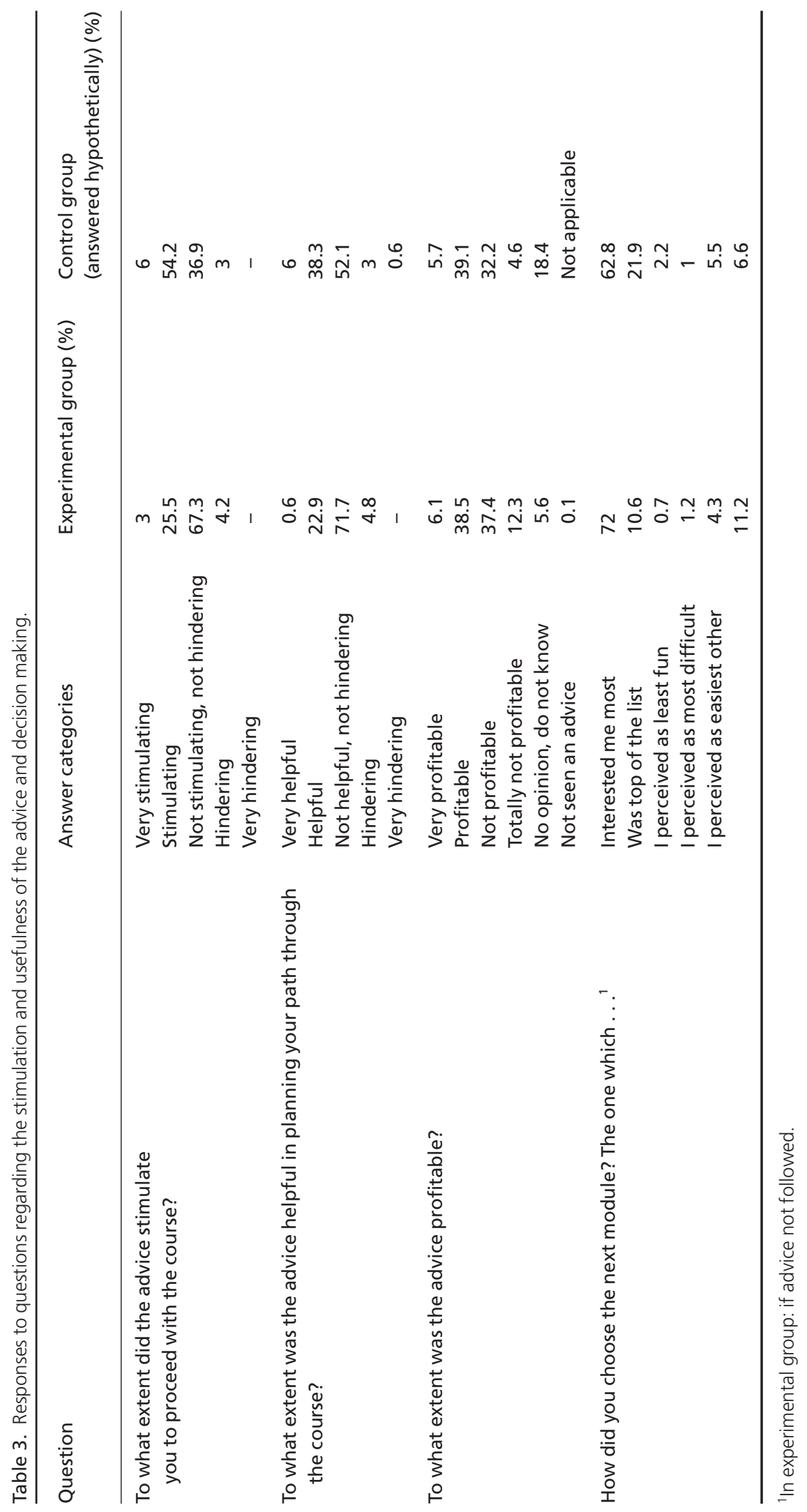


Table 4. Results of learner evaluation in experimental $(n=401)$ and control group $(n=399)$.

\begin{tabular}{|c|c|c|c|c|}
\hline & Experimental group & Control group & $\chi^{2}$-test $/ t$-test & $P$ \\
\hline Hours spent on course & & & $\chi^{2}(3)=1.99$ & NS \\
\hline Less than $10 \mathrm{~h}$ & 24.7 & 23.6 & & \\
\hline Between 10 and $20 \mathrm{~h}$ & 38.3 & 33.9 & & \\
\hline Between 20 and $30 \mathrm{~h}$ & 24.1 & 30.9 & & \\
\hline More than $30 \mathrm{~h}$ & 13 & 11.5 & & \\
\hline $\begin{array}{l}\text { Mean increase in knowledge and skills in Internet } \\
\text { domain as a result of the course }\end{array}$ & 2.59 & 2.42 & $t(341)=-2.14$ & $<0.05$ \\
\hline $\begin{array}{l}\text { Mean score on question whether students were of } \\
\text { the opinion that it would have been better for } \\
\text { understanding the course content to follow another } \\
\text { path through the course than actually followed }\end{array}$ & 0.60 & 0.52 & $t(339)=1.07$ & NS \\
\hline
\end{tabular}

NS, not significant.

Table 5. Means, standard deviations and pearson correlations.

\begin{tabular}{|c|c|c|c|c|c|c|c|c|}
\hline & $\mathrm{M}(n)$ & SD & 1 & 2 & 3 & 4 & 5 & 6 \\
\hline 1 adherence & $2.47(175)$ & 1.03 & - & $0.40 * *$ & $0.43 * *$ & $0.34 * *$ & 0.06 & $0.20 *$ \\
\hline 2 usefulness & $-0.11(178)$ & 1.23 & & - & $0.57 * *$ & $0.52 * *$ & -0.07 & 0.09 \\
\hline 3 trust & $2.05(168)$ & 0.69 & & & - & $0.39 * *$ & -0.04 & 0.09 \\
\hline 4 stimulation & $0.23(164)$ & 0.49 & & & & - & 0.04 & 0.20 ** \\
\hline 5 course completion ${ }^{1}$ & $5.61(410)$ & 0.92 & & & & & - & 0.35 ** \\
\hline 6 self-efficacy & $1.09(166)$ & 0.71 & & & & & & - \\
\hline
\end{tabular}

$* P<0.05 ; * * P<0.01$, two-sided.

${ }^{1}$ Number of course modules completed (range 0-11).

advice generated from the tool. This indicates that learners with high self-efficacy expectations completed more modules, adhered more often to the advice and were more convinced that the navigation tool helped them in planning the course. Noticeably, the number of modules completed is not correlated to any other subjective evaluation concept on which the opinion of learners was asked. Especially important is that the number of completed modules is not correlated to adherence to the advice, suggesting that course completion is not related to the adherence to the advice.

Adherence to the advice generated from the tool has strong associations with its perceived usefulness, the trust learners had in the advice, and the opinion learners held on the helpfulness of the advice in study planning and on the stimulating influence on proceeding with the course (the questions on helpfulness and stimulation were taken together as the stimulation-scale). This means the more trust, perceived usefulness and helpfulness, and perceived support in proceeding with a subsequent module, the more adherence to the advice generated from the tool. There were also strong correlations between the perceived usefulness of the tool and the trust learners had in the advice; the perceived usefulness and the opinion learners held on the perceived influence of the advice on planning. Finally, trust and stimulation were correlated.

We also explored the possible influence of the use of the navigation tool on self-efficacy expectations. A $t$-test (not presented in a table) showed no significant differences in self-efficacy levels $(\mathrm{t}(335)=-1.09, P=0.28)$ between the experimental $(\mathrm{M}=1.09, \mathrm{SD}=0.71)$ and control group $(\mathrm{M}=1.00, \mathrm{SD}=0.72)$. This means that the study provided no indications that self-efficacy expectations towards course completion are influenced by using the navigational support tool (i.e. receiving advice on the best next step to follow).

\section{Discussion}

This study aimed to provide indications for the refinement of a navigation tool developed to support distance 
learners by examining how learners evaluated the navigation tool, whether learners adhered to the advice, and whether the advice stimulated and helped them in planning the course. In addition, we explored the role of self-efficacy expectations in study progress and in adherence to the advice.

The study shows that slightly more than half of the learners in the experimental group followed the advice often or always. No related literature has been found on studies concerning adherence to advice in educational settings, but this amount is comparable with data from other domains, such as health care (La Greca \& Schuman 1995; Myers \& Midence 1998; World Health Organization 2003; DiMatteo 2004). The data reveal, however, that course completion has no correlation with adherence to the advice. This is hard to explain as the effectiveness study (Janssen et al. in press) showed positive effects of the tool on course completion. The measurement of adherence might not have been detailed and specific enough as the question was not posed for each module separately and only used one question measured by self-report and was asked retrospectively. We therefore need to interpret this finding with caution. Further research on the relation between adherence and course completion is recommended to validate our finding or to uncover the real relationship.

In line with results from studies of Bandura (1997), self-efficacy expectations and satisfaction with the tool were correlated. Contrary to our expectations, selfefficacy did not differ between the control and experimental group, which suggests that the navigation tool did not increase self-efficacy. In line with other studies (Multon \& Brown 1991; Tennant \& Pogson 1995; Vrught et al. 1997, 2002; Pietsch et al. 2003), selfefficacy was positively correlated with progress in the course. Learners in the experimental group reported a greater increase in Internet skills and knowledge than the control learners, which suggests a cognitive effect of the navigational support by the tool. Without influencing self-efficacy, the navigation tool might have had an effect on Internet skills and knowledge. Drawing hard conclusions on this effect is, however, difficult as we did not measure prior skills and knowledge of the responders. The effect on course progress was already shown by Janssen et al. (in press). In addition, it was found that self-efficacy and course completion are correlated. Causal inferences cannot be made as selfefficacy is only measured after course completion. The fact that self-efficacy did not differ between the two groups suggests that self-efficacy is not influenced by the navigation support tool.

With respect to tool refinement, results suggest informing learners of the goal of the advice and indicating the advantages of adhering to it. As usefulness is correlated to the trust learners have in the advice, clarifying the source of the advice might decrease learners' ambivalence towards its usefulness. As the study also indicated that stronger self-efficacy expectations result in better course progress, it is suggested to incorporate self-efficacy enhancing strategies in the navigational support. This could include information about successful comparable learners with whom the student can identify him or herself, thereby confirming the students' achievements and providing the learner with more information on how to approach a next module. It might also be useful to show the learners different paths to follow in a course in order to give them a sense of control (Tsai \& Tsai 2003).

The study is subject to certain limitations. The first limitation is the response rate of on average $60 \%$ for the socio-demographic and evaluation questions. Learners who were positive about the course and the navigation advice may have been more likely to respond to the evaluation questionnaire than those who were less positive. Hence, the sample from which the data are reported may not be representative. Second, the questions were asked retrospectively after the course and only cross-sectional. Therefore, conclusions about causal relationships cannot be made. It remains, for example, unclear whether perceiving the tool as very useful precedes adherence or that adherence precedes usefulness. Third, adherence is measured subjectively, on the whole course, after course completion and with only one question. This might have negatively affected the reliability of the measurement as adherence may have varied between modules and might have been difficult to remember after the course. Further experimentation will help to address these shortcomings.

In summary, the study provides important insights into distance learners' subjective evaluation of working with a navigation tool. It shows that more than half of the learners in the experimental group adhered to the advice and held the opinion that the advice stimulated to proceed with the course. Learners expressed a strong need to know the mechanisms behind the advice, and 
meeting this need is seen as an essential element in future versions of the tool.

\section{References}

Ajzen I. (1991) The theory of planned behavior. Organizational Behavior and Human Decision Processes 50, 179-211.

Bandura A. (1986) Social Foundations of Thought and Action: A Social Cognitive Theory. Prentice Hall, Englewood Cliffs, NJ.

Bandura A. (1997) Self-Efficacy: The Exercise of Control. Freeman, New York.

Cookson P.S. (1990) Persistence in distance education: a review. In Contemporary Issues in American Distance Education (ed. M.G. Moore), pp. 192-204. Pergamon Press, Oxford.

DiMatteo M.R. (2004) Variations in patients' adherence to medical recommendations: a quantitative review of 50 years of research. Medical Care 42, 200-209.

Frayne C.A. \& Geringer J.M. (1994) A social cognitive approach to examining joint venture general manager performance. Group and Organization Management 19, 240.

Fukuyama M.A., Probert B.S., Neimeyer G.J., Nevill D.D. \& Metzler A.E. (1988) Effects of DISCOVER on career selfefficacy and decision making of undergraduates. The Career Development Quarterly 37, 56-62.

Janssen J., Tattersall C., Waterink W., van de Berg B., van Es R., Bolman C. \& Koper R. (in press) Self-organising navigational support in lifelong learning: how predecessors can lead the way. Computers and Education (in press).

Jarupathirun S. \& Zahedi F.M. (in press) Exploring the influence of perceptual factors in the success of web-based spatial DSS. Decision Support Systems (in press).

Koper E.J.R. (2005) Increasing learner retention in a simulated learning network using indirect social interaction. Journal of Artificial Societies Social Simulation 8. Available at: http://jasss.soc.surrey.ac.uk/8/2/5.html (published 31 March 2005).

La Greca A.M. \& Schuman W.B. (1995) Adherence to prescribed medical regimes. In Handbook of Pediatric Psychology (ed. M.C. Roberts), pp. 55-83. The Guilford Press, New York.

Lorenzetti J. (2002) Before they drift away: two experts pool retention insights. Distance Education Report 6, 1-2.

Moonen J. (1997) The efficiency of telelearning. Journal of Asynchronous Learning Networks 1, 68-77.

Multon K.D. \& Brown S.D. (1991) Relation of self-efficacy beliefs to academic outcomes: a meta-analytic investigation. Journal of Counseling Psychology 38, 30-39.

Myers L.B. \& Midence K. (1998) Adherence to Medical Treatment in Medical Conditions. Harwoord Academic Publishers, Amsterdam.
Pietsch J., Walker R. \& Chapman E. (2003) The relationship among self-concept, self-efficacy, and performance in mathematics during secondary school. Journal of Educational Psychology 3, 589-603.

Rovai A.P. (2003) In search of higher persistence rates in distance education online programs. Internet and Higher Education 6, 1-16.

Simpson O. (2004) Access, Retention and Course Choice in Online, Open and Distance Learning. Paper presented at the Third Eden Research Workshop, Oldenburg, Germany. Available at: http://www.eurodl.org/materials/contrib/ 2004/Ormond_Simpson.html (accessed 5 July 2005).

Stajkovic A.D. \& Luthans F. (1998) Self-efficacy and workrelated performance: a meta-analysis. Psychological Bulletin 124, 240-261.

Tattersall C., Manderveld J., van den Berg B., van Es R., Janssen J. \& Koper R. (2005) Self organising wayfinding support for lifelong learners. Education and Information Technologies 10, 111-123.

Tennant B.M. \& Pogson P. (1995) Learning and change in the adults years: a developmental perspective. Adult Education Quarterly 46, 177-181.

Tsai M.J. \& Tsai C.C. (2003) Information searching strategies in web-based science learning: the role of Internet self-efficacy. Innovations in Education and Teaching Internation 40, 43-50.

Venkathesh V. \& Davis F.D. (1996) A model of the antecedents of perceived ease of use: development and test. Decision Sciences 27, 451-481.

Vrught A., Langereis M.P. \& Hoogstraten J. (1997) Academic self-efficacy and malleability of relevant capabilities as predictors of exam performance. Journal of Experimental Education 66, 61-74.

Vrught A., Oort F.J. \& Zeeberg C. (2002) Goal orientations, perceived self-efficacy and study results amongst beginners and advanced students. British Journal of Educational Psychology 72, 385-397.

Waiman C., Eldon Y.L. \& Lester W.Y. (2003) Multimedia learning system and its effect on self-efficacy in database modelling and design: an exploratory study. Computers and Education 41, 249-270.

World Health Organization (2003) Adherence to Long Term Therapies: Evidence for Action. World Health Organization, Geneva.

Xenos M., Pierrakeas C. \& Pintelas P. (2002) A survey on student dropout rates and dropout causes concerning the students in the course of informatics of the Hellenic Open University. Computers and Education 39, 361377.

Yorke M. (1999) Leaving Early. Undergraduate Non-completion in Higher Education. Falmer Press, London. 